\title{
Características Distributivas e Impacto de Reformas Tributárias Sobre o Bem-Estar das Famílias no Brasil
}

\author{
Diogo Baerlocher Carvalho*, Rozane Bezerra de Siqueira ${ }^{\dagger}$, José \\ Ricardo Bezerra Nogueira ${ }^{\ddagger}$
}

\footnotetext{
Conteúdo: 1. Introdução; 2. Distribuição da Carga Tributária; 3. Método; 4. Resultados; 5. Conclusões; A. Estimações; B. Grupos de Consumo.

Palavras-chave: Características distributivas; Reforma tributária; Bem-Estar.

Códigos JEL: H21, H23, I38
}

Este trabalho calcula as características distributivas dos bens e serviços consumidos pelas famílias no Brasil, usando a POF 2008-2009, e utiliza essa informação para elaborar propostas alternativas de reforma tributária indireta. O impacto das reformas sobre o bem-estar é avaliado usando o conceito de "variação equivalente" e o sistema de demanda quase ideal na forma quadrática (QUAIDS). Os resultados mostram que os três itens de consumo familiar com características distributivas mais elevadas são combustível doméstico, fumo e cesta básica de alimentos, e os três itens com características distributivas mais baixas são combustível automotivo, bebidas alcoólicas e transporte privado. As reformas baseadas nas características distributivas são progressivas, sendo que a mais progressiva resulta em um aumento de bem-estar das famílias mais pobres equivalente a um aumento de $8,2 \%$ no seu consumo, e em uma perda de bem-estar para as famílias mais ricas equivalente a uma redução de 5,6\% no seu consumo.

The present work estimates the distributive characteristic of goods and services consumed by Brazilian families as reported in POF 2008-09 and uses this information to design alternative indirect tax reform proposals. The impact of the reforms on welfare is assessed using the equivalent variation concept and the quadratic almost ideal demand system (QUAIDS). The results show that the three consumption goods with the highest distributive

\footnotetext{
*University of Illinois at Urbana-Champaign. E-mail: dcarval2@illinois .edu

† Professora e pesquisadora do Departamento de Economia, UFPE. E-mail: rozane_siqueira@yahoo.com. br

${ }^{\ddagger}$ Professor e pesquisador do Departamento de Economia, UFPE. E-mail: jrbnogueira@yahoo.com. br
} 
characteristics are domestic fuel, tobacco and basic food, and the three consumption goods with the lowest distributive characteristics are automotive fuel, alcoholic beverages and private transport. All reforms based on the distributive characteristics are progressive, with the most progressive of them resulting in a welfare gain to the poorest families equivalent to a $8.2 \%$ rise in their consumption, and in a welfare loss to the richest families equivalent to a $5.6 \%$ decrease in their consumption.

\section{INTRODUÇÃO}

A carga tributária no Brasil, de quase 36\% do PIB, é aproximadamente igual à carga tributária média dos países da $O C D E$ e é muito superior à carga tributária de países com renda per capita similar à do Brasil. Quase metade (48\%) dessa carga corresponde a tributos sobre bens e serviços. ${ }^{1}$ Assim, mesmo as classes de renda mais baixas comprometem parte importante de seus orçamentos com o pagamento de tributos.

Com a estrutura vigente de alíquotas tributárias, há uma tendência de piora nessa situação, como observa Siqueira et alii (2012). Isso porque nos últimos anos tem havido mudanças substanciais nas cestas de consumo das famílias mais pobres, com redução da participação de itens menos tributados (como alimentos básicos) e aumento da participação de itens fortemente tributados (como comunicação e combustível automotivo). Em vista disso, vários analistas têm defendido reformas nas alíquotas dos tributos que incidem sobre o consumo com o intuito de tornar o sistema tributário mais equitativo. Com efeito, no texto sobre reforma tributária elaborado pelo Ministério da Fazenda (2008), o governo propõe rever a estrutura de alíquotas tributárias a fim de tornar o sistema "mais justo e menos oneroso para a parcela mais pobre da população".

Este artigo tem dois objetivos. O primeiro é calcular as "características distributivas" de 18 categorias de bens e serviços consumidos pelas famílias no Brasil, usando os microdados da Pesquisa de Orçamentos Familiares (POF) 2008-2009. O cálculo de "características distributivas" foi proposto originalmente por Feldstein (1972) e leva em conta tanto a participação dos bens e serviços na cesta de consumo das famílias mais pobres, relativamente às mais ricas, quanto o grau de aversão da sociedade à desigualdade de consumo. Essa abordagem permite ordenar os itens de consumo das famílias, segundo critérios exclusivamente distributivos, para diferentes níveis de preocupação com equidade.

O segundo objetivo do artigo é avaliar o impacto sobre o bem-estar das famílias de reformas alternativas na tributação de bens e serviços. As características distributivas serão usadas como guia para elaboração das propostas de reforma a serem simuladas. Os impactos das reformas sobre o bemestar das famílias em diferentes estratos de despesa serão mensurados usando a medida monetária de bem-estar "variação equivalente", calculada com base no sistema de demanda quase ideal na forma quadrática (QUAIDS), proposto por Banks et alii (1997).

O artigo está estruturado da seguinte forma. Após esta introdução, a seção 2 descreve a estrutura de consumo das famílias e estima a distribuição da carga tributária por décimo de despesa familiar e por categoria de bem tributado. A seção 3 apresenta a metodologia de cálculo das características distributivas dos bens e serviços e de mensuração do impacto de reformas tributárias sobre o de bem-estar das famílias. Na seção 4 , são apresentados os resultados. Por fim, são apresentadas as considerações finais.

\footnotetext{
${ }^{1}$ Secretaria da Receita Federal (2010).
} 


\section{DISTRIBUIÇÃO DA CARGA TRIBUTÁRIA}

Nesta seção investiga-se a distribuição da carga tributária indireta sobre as famílias brasileiras. Para isso, é preciso notar que a carga incidente sobre as famílias depende fundamentalmente de duas variáveis: da estrutura de gasto familiar com consumo e das alíquotas tributárias efetivas sobre os bens e serviços de consumo familiar.

A Tabela 1 mostra as parcelas orçamentárias médias (POMs) das famílias em diferentes décimos de despesa total de consumo, sendo o consumo total desagregado em 18 itens. ${ }^{2}$ Notam-se alguns itens cujo peso sobre o orçamento dos mais pobres são maiores, como cesta básica, eletricidade, combustível doméstico e aluguel. Os consumidores do primeiro décimo gastam uma parcela $270,7 \%$ maior de sua despesa total com cesta básica do que os consumidores do último décimo. Para eletricidade, combustível doméstico e aluguel esses valores são 181,1\%, 1.027\% e 73,5\%, respectivamente. Bens cujas POMs aumentam junto com os décimos de despesas são: combustível automotivo, transporte privado e outros bens e serviços. Os consumidores do último décimo gastam 596,3\% a mais com combustível automotivo do que consumidores do primeiro décimo de despesa. Esses valores são de 509,1\% e 320,6\% para transporte privado e outros bens e serviços, respectivamente.

Tabela 1: Parcelas orçamentárias médias por décimo de despesa familiar per capita em 2009 (\%)

\begin{tabular}{lccccccccccc}
\hline \multirow{1}{*}{\multicolumn{1}{c}{ Item }} & \multicolumn{7}{c}{ Décimos de despesa familiar per capita } & \multicolumn{1}{c}{ Total } \\
\cline { 2 - 9 } & 1 & 2 & 3 & 4 & 5 & 6 & 7 & 8 & 9 & 10 & \\
\hline Cesta Básica & 17,7 & 16,8 & 15,4 & 14,0 & 13,3 & 12,5 & 10,9 & 9,9 & 8,1 & 4,8 & 12,3 \\
Outros alimentos & 9,7 & 11,1 & 11,4 & 11,3 & 11,2 & 11,5 & 11,5 & 11,6 & 10,9 & 9,6 & 11,0 \\
Bebidas alcoólicas & 0,0 & 0,1 & 0,2 & 0,3 & 0,4 & 0,5 & 0,5 & 0,6 & 0,7 & 0,5 & 0,4 \\
Fumo & 1,1 & 1,0 & 1,0 & 0,9 & 0,9 & 0,8 & 0,7 & 0,6 & 0,5 & 0,3 & 0,8 \\
Vestuário & 6,5 & 6,5 & 6,6 & 6,3 & 5,9 & 6,1 & 5,8 & 5,6 & 5,3 & 5,2 & 6,0 \\
Eletricidade & 5,1 & 4,6 & 4,3 & 4,3 & 3,9 & 3,7 & 3,3 & 3,0 & 2,5 & 1,8 & 3,6 \\
Combustível doméstico & 4,4 & 3,2 & 2,5 & 2,0 & 1,8 & 1,5 & 1,2 & 0,9 & 0,7 & 0,4 & 1,9 \\
Bens e serviços domésticos & 8,3 & 8,4 & 8,6 & 8,5 & 8,9 & 8,8 & 9,5 & 9,6 & 10,3 & 12,7 & 9,3 \\
Saúde & 5,3 & 5,8 & 5,8 & 6,3 & 6,8 & 6,8 & 7,1 & 6,9 & 7,4 & 7,7 & 6,6 \\
Combustível automotivo & 0,7 & 1,3 & 1,6 & 2,2 & 2,9 & 3,2 & 3,9 & 4,5 & 4,9 & 4,9 & 3,0 \\
Transporte público & 2,8 & 3,5 & 3,7 & 4,1 & 3,5 & 3,4 & 2,7 & 2,4 & 1,8 & 1,0 & 2,9 \\
Transporte privado & 2,8 & 3,8 & 4,1 & 5,0 & 5,9 & 6,6 & 7,9 & 9,7 & 12,7 & 16,8 & 7,5 \\
Comunicação & 2,0 & 2,6 & 3,3 & 3,7 & 3,8 & 3,9 & 4,0 & 4,1 & 3,9 & 3,5 & 3,5 \\
Educação & 1,0 & 0,9 & 0,9 & 0,9 & 1,1 & 1,3 & 1,5 & 2,1 & 2,9 & 2,7 & 1,5 \\
Higiene e cuidados pessoais & 3,1 & 3,4 & 3,3 & 3,6 & 3,4 & 3,4 & 3,3 & 3,1 & 2,8 & 2,5 & 3,2 \\
Recreação e cultura & 2,7 & 2,6 & 2,8 & 2,8 & 2,8 & 2,9 & 2,9 & 3,1 & 3,0 & 3,6 & 2,9 \\
Aluguel & 24,9 & 21,8 & 21,6 & 20,5 & 19,7 & 18,8 & 18,6 & 16,7 & 15,5 & 14,3 & 19,2 \\
Outros bens e serviços & 1,8 & 2,6 & 3,0 & 3,3 & 3,7 & 4,2 & 4,8 & 5,6 & 6,0 & 7,7 & 4,3 \\
\hline
\end{tabular}

Fonte: elaboração própria. Dados: Pesquisa de Orçamento Familiar 2008-2009, IBGE.

Outros itens apresentam comportamentos que não podem ser considerados monotônicos. O item outros alimentos apresenta POMs maiores entre consumidores dos décimos intermediários. Comunicação, transporte público e higiene e cuidados pessoais também seguem o mesmo comportamento. O grupo

\footnotetext{
${ }^{2}$ A Tabela B-2 do Apêndice B apresenta a composição de cada um dos 18 itens estudados.
} 
bebidas alcoólicas tem as POMs crescentes com os décimos de gasto até que há uma queda do nono para o último. O mesmo ocorre com educação, porém as quedas ocorrem no primeiro e último décimo. O fumo é praticamente decrescente havendo aumento apenas entre o quarto e o quinto décimo de despesa. Já o grupo bens e serviços domésticos apresenta comportamento crescente entre os décimos, exceto entre o terceiro e o quarto. Os gastos com saúde e recreação e cultura também são crescentes com algumas exceções.

Pela análise da Tabela 1, percebe-se a heterogeneidade dos padrões de consumo das famílias no Brasil. Bens como cesta básica, aluguel e combustível doméstico mostram-se como itens de primeira necessidade devido a suas altas POMs, principalmente para os estratos com menores despesas. Itens como bens e serviços domésticos, transporte privado e combustível automotivo, ao contrário, apresentam características de bens de luxo dadas suas POMs elevadas nos décimos de despesa mais altos.

A fim de observar as mudanças recentes na estrutura de consumo familiar, a Tabela 2 mostra a evolução dos padrões de consumo das famílias brasileiras no período entre as duas últimas Pesquisas de Orçamentos Familiares. Note que, além das POMs da população total, a tabela mostra as parcelas orçamentárias para o primeiro e o último décimo de despesa.

Tanto em 2003 como em 2009, o item aluguel é o responsável pela maior POM entre os grupos de consumo, representando cerca de $19 \%$ da despesa familiar total. Em seguida, cesta básica e outros alimentos são os itens mais importantes. Vale ressaltar que o item outros alimentos inclui gastos com alimentação fora do domicílio. Para a classe mais pobre, cesta básica era o item com maior participação no gasto em 2003 com POM igual 24,57\%. Com a grande redução na POM desse item, em 2009, os gastos com aluguel passaram a ser mais representativos para o décimo mais baixo de despesa. Na camada mais rica, o aluguel representava a maior parcela de gasto, em 2003 , com $14,72 \%$. No entanto, os gastos com transporte privado se tornaram mais representativos em 2009 participando de $16,18 \%$ do consumo dos $10 \%$ mais ricos.

Os principais itens que conquistaram espaço na lista de consumo entre as POFs são higiene e cuidados pessoais, saúde e outros alimentos com aumentos de $29,6 \%, 23,4 \%$ e $17,4 \%$, respectivamente. Os itens com maiores reduções em suas POMs são combustível doméstico, recreação e cultura e fumo com quedas de $37,1 \%, 22,6 \%$ e $22,1 \%$, respectivamente. Note a aparente substituição entre o consumo de cesta básica que teve redução de $19,5 \%$ e outros alimentos entre as pesquisas. Outro ponto de destaque é o aumento de $147,4 \%$ nos gastos com comunicação entre os consumidores do estrato mais pobre. Destacam-se também os aumentos nos gastos com combustível automotivo $(59,1 \%)$ e saúde $(40,9 \%)$ para essa camada da população. Entre os itens com maiores reduções nesse décimo estão combustível doméstico, cesta básica e fumo com quedas de $42.4 \%, 27,8 \%$ e $26,7 \%$, respectivamente. No estrato mais rico, os grupos de consumo que ganharam espaço foram vestuário, transporte privado e saúde com aumentos de $37,2 \%, 16,5 \%$ e $15,5 \%$, respectivamente. Os itens nesse estrato cujas POMs tiveram maior redução são recreação e cultura, fumo e educação com perdas de participação na cesta de consumo de $38,9 \%, 33,9 \%$ e $33,4 \%$, respectivamente.

Vale notar o comportamento dos gastos com educação entre as pesquisas. Em 2003, a participação do gasto com educação no orçamento dos $10 \%$ mais ricos era quase quatro vezes maior do que a participação no orçamento dos $10 \%$ mais pobres, enquanto que, em 2009, a POM de educação no último décimo não chega a três vezes a POM do primeiro décimo. Cabe ainda ressaltar que entre as duas pesquisas os padrões de consumo das famílias se tornaram mais homogêneos, dificultando a promoção de redistribuição via tributação indireta. À medida que as cestas se tornam mais parecidas, a diferenciação de alíquotas com o intuito de onerar menos as camadas mais pobres se tornará mais dificil e ineficaz.

As alíquotas tributárias efetivas incidentes sobre as categorias de bens e serviços utilizadas neste estudo foram obtidas a partir das alíquotas efetivas estimadas por Siqueira et alii (2011) com base na Matriz de Insumo-Produto de 2005 (IBGE, 2008). O método utilizado por esses autores parte da receita efetivamente arrecadada de cada atividade produtiva e supõe que os tributos que recaem sobre insumos são totalmente transferidos para frente em cada estágio da cadeia de produção, até o consumidor final. Os tributos incorporados no cálculo são: Imposto sobre a Circulação de Mercadorias e sobre Ser- 
Tabela 2: Evolução das parcelas orçamentária médias entre 2003 e 2009 (\%)

\begin{tabular}{lrrrrrr}
\hline \multirow{2}{*}{ Item } & \multicolumn{2}{c}{ Primeiro Décimo } & Último Décimo & \multicolumn{2}{c}{ Total } \\
\cline { 2 - 7 } & 2003 & 2009 & 2003 & 2009 & 2003 & 2009 \\
\hline Cesta Básica & 24,57 & 17,74 & 4,81 & 4,78 & 15,34 & 12,35 \\
Outros alimentos & 8,32 & 9,74 & 9,40 & 9,59 & 9,35 & 10,98 \\
Bebidas alcoólicas & 0,02 & 0,03 & 0,55 & 0,54 & 0,36 & 0,39 \\
Fumo & 1,54 & 1,13 & 0,39 & 0,26 & 0,99 & 0,77 \\
Vestuário & 6,10 & 6,51 & 3,79 & 5,20 & 5,53 & 5,98 \\
Eletricidade & 3,68 & 5,12 & 1,96 & 1,82 & 3,37 & 3,64 \\
Combustível doméstico & 7,56 & 4,35 & 0,50 & 0,39 & 2,97 & 1,87 \\
Bens e serviços domésticos & 7,54 & 8,28 & 11,78 & 12,72 & 9,13 & 9,35 \\
Saúde & 3,78 & 5,33 & 6,67 & 7,70 & 5,35 & 6,60 \\
Combustível automotivo & 0,44 & 0,70 & 5,78 & 4,91 & 2,73 & 3,02 \\
Transporte público & 2,35 & 2,83 & 1,16 & 0,98 & 2,70 & 2,89 \\
Transporte privado & 2,59 & 2,76 & 14,44 & 16,82 & 6,83 & 7,53 \\
Comunicação & 0,81 & 2,01 & 4,24 & 3,47 & 3,30 & 3,48 \\
Educação & 1,10 & 0,99 & 4,08 & 2,72 & 1,79 & 1,54 \\
Higiene e cuidados pessoais & 2,32 & 3,09 & 2,20 & 2,48 & 2,46 & 3,18 \\
Recreação e cultura & 2,64 & 2,67 & 5,82 & 3,55 & 3,75 & 2,90 \\
Aluguel & 22,29 & 24,88 & 14,72 & 14,34 & 19,56 & 19,24 \\
Outros bens e serviços & 2,34 & 1,84 & 7,71 & 7,73 & 4,48 & 4,28 \\
\hline
\end{tabular}

Fonte: elaboração própria. Dados: Pesquisa de Orçamento Familiar 2002-2003 e 2008-2009, IBGE.

viços de Transporte Interestadual e Intermunicipal e de Comunicação (ICMS), Imposto sobre Produtos Industrializados (IPI), Imposto de Importação (II), e uma categoria denominada outros impostos menos subsídios. Para cada um desses tributos, Siqueira et alii (2011) estimou a alíquota tributária efetiva que incide sobre cada produto discriminado na Matriz. No presente estudo, essas alíquotas são aplicadas à POF 2008-09 para obter a distribuição da carga tributária indireta entre as famílias em diferentes estratos de despesa, por item de consumo. Os resultados são mostrados na Tabela 3. As maiores alíquotas tributárias são referentes a fumo , eletricidade e bebidas alcoólicas, com, respectivamente, 45,8\%, 42,8\% e $41,0 \%$. As mais baixas são as de aluguel, educação e outros bens e serviços, com 0,7\%, 9,3\% e 11,6\%, respectivamente.

A parcela total dos gastos destinada ao pagamento dos tributos indiretos é aproximadamente $17 \%$. Note que essa parcela varia muito pouco entre os décimos de despesa. O nono décimo - aquele com maior carga - tem uma parcela de $17,26 \%$ de seus gastos destinada a tributação indireta, enquanto 
Tabela 3: Carga tributária dos impostos indiretos por décimo de despesa familiar per capita e alíquotas efetivas médias (\%)

\begin{tabular}{|c|c|c|c|c|c|c|c|c|c|c|c|c|}
\hline \multirow{2}{*}{ Itens } & \multicolumn{10}{|c|}{ Décimos de despesa familiar per capita } & \multirow{2}{*}{ Total } & \multirow{2}{*}{ Alíquotas } \\
\hline & 1 & 2 & 3 & 4 & 5 & 6 & 7 & 8 & 9 & 10 & & \\
\hline Cesta Básica & 2,31 & 2,19 & 2,00 & 1,83 & 1,75 & 1,62 & 1,42 & 1,30 & 1,06 & 0,62 & 1,61 & 13,00 \\
\hline Outros Alimentos & 1,73 & 2,02 & 2,08 & 2,08 & 2,07 & 2,12 & 2,13 & 2,15 & 2,03 & 1,77 & 2,02 & 18,44 \\
\hline Bebidas Alcoólicas & 0,01 & 0,05 & 0,09 & 0,12 & 0,16 & 0,21 & 0,22 & 0,24 & 0,29 & 0,22 & 0,16 & 40,99 \\
\hline Fumo & 0,52 & 0,47 & 0,44 & 0,41 & 0,42 & 0,37 & 0,30 & 0,26 & 0,23 & 0,12 & 0,35 & 45,84 \\
\hline Vestuário & 0,87 & 0,87 & 0,88 & 0,85 & 0,79 & 0,83 & 0,79 & 0,76 & 0,71 & 0,71 & 0,81 & 13,51 \\
\hline Eletricidade & 2,19 & 1,95 & 1,84 & 1,82 & 1,67 & 1,56 & 1,43 & 1,28 & 1,08 & 0,78 & 1,56 & 42,82 \\
\hline Combustível Doméstico & 1,09 & 0,81 & 0,63 & 0,50 & 0,45 & 0,39 & 0,31 & 0,22 & 0,17 & 0,10 & 0,47 & 25,09 \\
\hline Bens e Serviços Domésticos & 1,96 & 1,93 & 1,96 & 1,91 & 1,90 & 1,87 & 1,89 & 1,81 & 1,80 & 1,73 & 1,88 & 18.41 \\
\hline Saúde & 1,29 & 1,37 & 1,34 & 1,42 & 1,47 & 1,43 & 1,45 & 1,32 & 1,33 & 1,23 & 1,37 & 19,13 \\
\hline Combustível Automotivo & 0,18 & 0,33 & 0,41 & 0,57 & 0,76 & 0,84 & 1,00 & 1,17 & 1,26 & 1,27 & 0,78 & 26,18 \\
\hline Transporte Público & 0,48 & 0,60 & 0,62 & 0,69 & 0,60 & 0,59 & 0,46 & 0,41 & 0,31 & 0,17 & 0,49 & 17,00 \\
\hline Transporte Privado & 0,55 & 0,77 & 0,83 & 1,04 & 1,25 & 1,40 & 1,71 & 2,15 & 2,90 & 3,91 & 1,65 & 23,35 \\
\hline Comunicação & 0,74 & 0,98 & 1,27 & 1,43 & 1,48 & 1,51 & 1,59 & 1,61 & 1,54 & 1,37 & 1,35 & 38,97 \\
\hline Educação & 0,20 & 0,16 & 0,14 & 0,13 & 0,13 & 0,14 & 0,14 & 0,18 & 0,23 & 0,22 & 0,17 & 9,35 \\
\hline Higiene e Cuidados Pessoais & 0,70 & 0,77 & 0,76 & 0,81 & 0,78 & 0,75 & 0,73 & 0,68 & 0,62 & 0,52 & 0,71 & 22,46 \\
\hline Recreação e Cultura & 0,82 & 0,80 & 0,83 & 0,84 & 0,86 & 0,88 & 0,88 & 0,96 & 0,92 & 1,08 & 0,89 & 30.68 \\
\hline Aluguel & 0,16 & 0,18 & 0,17 & 0,20 & 0,15 & 0,17 & 0,16 & 0,15 & 0,14 & 0,14 & 0,16 & 0,75 \\
\hline Outros Bens e Serviços & 0,20 & 0,30 & 0,33 & 0,35 & 0,41 & 0,47 & 0,52 & 0,62 & 0,64 & 0,83 & 0,47 & 11,58 \\
\hline Total & 16,01 & 16,54 & 16,64 & 17,04 & 17,10 & 17,16 & 17,13 & 17,25 & 17,26 & 16,79 & 16,89 & \\
\hline
\end{tabular}

Fonte: Elaboração Própria. Dados: POF 2008-2009, IBGE.

o primeiro décimo destina $16,01 \%$. Os itens com maior peso nos gastos da população como um todo são outros alimentos, bens e serviços domésticos e transporte privado, com cargas de $2 \%, 1,9 \%$ e $1,6 \%$, respectivamente. Por outro lado, os itens com menor peso são bebidas alcoólicas, aluguel e educação, com $0,16 \%, 0,16 \%$ e $0,17 \%$, respectivamente. Os itens cesta básica, eletricidade e combustível doméstico apresentam cargas decrescentes, enquanto combustível automotivo, transporte privado e outros bens $e$ serviços têm cargas crescentes.

\section{MÉTODO}

Nesta seção, o conceito e cálculo das características distributivas são apresentados a partir da teoria de reformas tributárias marginais. Além disso, também é apresentado o método utilizado para mensurar os ganhos/perdas de bem-estar gerados por reformas não-marginais. Os dados utilizados provêm da Pesquisa de Orçamentos Familiares realizada pelo IBGE entre julho de 2008 e junho de 2009. Trata-se da pesquisa de orçamento familiar mais recente disponível e apenas a terceira de âmbito nacional para o Brasil.

\subsection{Cálculo da característica distributiva}

O arcabouço teórico de reformas tributárias marginais proposto por Ahmad e Stern (1984) será utilizado para definir as características distributivas como instrumento para analisar reformas tributárias de caráter redistributivo. A primeira hipótese imposta no modelo é que o vetor de preços dos produtores, $\mathbf{p}$, é fixo. Assim, ao ajustar o vetor de alíquotas, t, o governo é capaz de controlar o vetor de preços aos consumidores, $\mathbf{q}$, de modo que 


$$
\mathbf{q}=\mathbf{p}+\mathbf{t}
$$

De acordo com Dixit (1975), a hipótese de p fixo só é sustentável quando todos os bens e serviços são produzidos por firmas competitivas com retornos constantes de escala. Portanto, assume-se essas hipóteses simplificadoras para o comportamento da firma. Dessa forma, temos que $\Delta \mathbf{q}=\Delta \mathbf{t}$.

No modelo existem $H$ famílias que escolhem a cesta de bens, $\mathbf{x}^{h}$, que maximiza suas funções utilidade, $u^{h}\left(\mathbf{x}^{h}\right)$, sujeitas às suas restrições orçamentárias. Assim, a maximização das utilidades está indiretamente relacionada à escolha dos preços e, consequentemente, à escolha do vetor de alíquotas tributárias. A função utilidade indireta é dada por:

$$
v^{h}\left(\mathbf{q}, y^{h}\right)=u^{h}\left(\mathbf{x}^{h}\left(\mathbf{q}, y^{h}\right)\right) \text { para } h=1, \ldots, H,
$$

em que $y^{h}$ é a renda da família $h$.

A teoria de tributação ótima baseia-se na maximização de uma função de bem-estar social sujeita à restrição de arrecadação do governo:

$$
\begin{array}{ll}
\underset{\mathbf{t}}{\operatorname{Maximizar}} & \mathrm{W}(\mathbf{t})=\mathrm{W}\left(v^{1}\left(\mathbf{t}, y^{1}\right), v^{2}\left(\mathbf{t}, y^{2}\right), \ldots, v^{H}\left(\mathbf{t}, y^{H}\right)\right) \\
\text { Sujeito a } & R=\sum_{i} \sum_{h} t_{i} x_{i}^{h},
\end{array}
$$

em que $W(\mathbf{t})$ é uma função de bem-estar social do tipo Bergson-Samuelson indireta, ou seja, em função dos preços e da renda. Assim, o problema da reforma tributária consiste em encontrar um vetor de mudanças $\Delta t$ tal que $\Delta W \geqq 0$ e $\Delta R \geqq 0$, com uma das desigualdades estrita. Essa melhora de bem-estar pode ser encontrada se o custo marginal em termos de bem-estar social de um aumento na arrecadação através do bem $i$ exceder o mesmo para o bem $j$. Esse custo marginal, $\lambda_{i}$, é o preço-sombra do problema de otimização (1), sendo:

$$
\lambda_{i}=-\frac{\partial W}{\partial t_{i}} / \frac{\partial R}{\partial t_{i}}
$$

O sinal negativo ressalta o fato de se tratar de um custo, uma vez que o aumento nos impostos deve reduzir o bem-estar. Note que podemos escrever o termo do numerador como

$$
\frac{\partial W}{\partial t_{i}}=\sum_{h=1}^{H} \frac{\partial W}{\partial v^{h}} \frac{\partial v^{h}}{\partial t_{i}}
$$

Utilizando a identidade de Roy,

$$
\frac{\partial v^{h}}{\partial t_{i}}=-\frac{\partial v^{h}}{\partial y^{h}} x_{i}^{h}=-\alpha^{h} x_{i}^{h},
$$

em que $\alpha^{h}$ é a utilidade marginal da renda. Além disso, define-se como a utilidade marginal social da renda da família $h$ ou como peso social

$$
\beta^{h}=\frac{\partial W}{\partial v^{h}} \frac{\partial v^{h}}{\partial y^{h}}=\frac{\partial W}{\partial v^{h}} \alpha^{h} .
$$

Realizadas as devidas substituições, a equação (2) pode ser reescrita da seguinte forma:

$$
\lambda_{i}=\frac{\sum_{h} \beta^{h} x_{i}^{h}}{X_{i}+\sum_{k} t_{k}\left(\frac{\partial X_{k}}{\partial t_{i}}\right)} .
$$


De acordo com Ahmad e Stern (1991) pode-se reescrever a equação (4) utilizando as definições de característica distributiva, $d_{i}$, elasticidade do imposto, $\eta_{i}$, e a parcela do $i$-ésimo bem na receita tributária, $\rho_{i}$, tal que

$$
\lambda_{i}=\frac{\rho_{i} d_{i}}{\eta_{i}}
$$

em que,

$$
d_{i}=\frac{\sum_{h}^{H} \beta^{h} x_{i}^{h}}{X_{i}}, \quad \rho_{i}=\frac{t_{i} X_{i}}{R}, \quad \text { e } \quad \eta_{i}=\frac{t_{i}}{R} \frac{\partial R}{\partial t_{i}} .
$$

A equação (5) mostra de forma clara a separação entre preocupações de eficiência, representada por $\rho_{i} / \eta_{i}$, e de equidade, representada pela característica distributiva. Dada a razão $\rho_{i} / \eta_{i}$, quanto maior a característica distributiva de um bem, maior será o custo marginal social da tributação desse bem, indicando que ele é um candidato a ter alíquotas reduzidas. Feldstein (1972) definiu a característica distributiva de um bem como sendo a média ponderada das utilidades marginais sociais dos indivíduos, em que os pesos são o nível de consumo desse bem por cada indivíduo. Neste trabalho, o cálculo das características distributivas é realizado tal como em Newbery (1995):

$$
d_{i} \equiv \frac{\sum_{h} \beta^{h} x_{i}^{h}}{\bar{\beta} X_{i}}
$$

em que $\bar{\beta}=\frac{1}{H} \sum_{h} \beta^{h}$ é a média dos pesos sociais. Dessa forma, $d_{i}$ representa o quão concentrado o consumo do bem $i$ se encontra sobre aqueles indivíduos com elevados pesos sociais. 0 cálculo de $\beta$ é realizado, como na maioria das análises empíricas realizadas sobre o tema, assumindo-se uma função de bem-estar social do tipo proposto por Atkinson (1970), definida pela soma das rendas individuais ponderadas por um termo de aversão à desigualdade denotado por $e$. Assim

$$
W=\frac{1}{1-e} \sum_{h=1}^{H}\left(y^{h}\right)^{1-e}, \text { para } e \neq 1
$$

e

$$
W=\sum_{h=1}^{H} \log \left(y^{h}\right), \text { para } e=1 .
$$

Dessa forma, substituindo as derivadas dessa função na equação (3), e ordenando as famílias em ordem crescente de renda per capita, calculamos os pesos sociais da seguinte forma:

$$
\beta^{h}=\left(\frac{y^{1}}{y^{h}}\right)^{e}
$$

\subsection{Mensuração de variações no bem-estar das famílias}

De forma a avaliar as mudanças de bem-estar proporcionadas por reformas tributárias baseadas nas características distributivas, será calculada a variação equivalente para as famílias da amostra. Tratase de uma medida de bem-estar de métrica monetária que mensura o valor que as famílias estariam dispostas a receber no lugar da variação na estrutura de impostos.

Para obter a variação equivalente, é necessário estimar um sistema de demanda, uma vez que é preciso saber a reação das famílias a alterações nos preços. Para isso, será usado o sistema de demanda quase ideal na forma quadrática (QUAIDS), proposto por Banks et alii (1997) como uma generalização do sistema de demanda quase ideal (AIDS) de Deaton e Muellbauer (1980). Esse sistema define a parcela orçamentária do bem $i$ da família $h$ como 


$$
w_{i}^{h}=\alpha_{i}+\sum_{k=1}^{n} \gamma_{i k} \log q_{k}+\xi_{i} \log \left(\frac{y^{h}}{P}\right)+\frac{\theta_{i}}{\prod_{k} q_{k}^{\xi_{k}}}\left[\log \left(\frac{y^{h}}{P}\right)\right]^{2},
$$

em que $P$ é um índice de preços dado por

$$
\log P=\alpha_{0}+\sum_{i} \alpha_{i} \log q_{i}+0,5 \sum_{i} \sum_{k} \gamma_{i k} \log q_{i} \log q_{k}
$$

Esse sistema segue as restrições de aditividade, homogeneidade e simetria sugeridas pela teoria microeconômica tal que

$$
\begin{array}{cc}
\text { (Aditividade) } & \sum_{i} \alpha_{i}=1, \quad \sum_{i} \gamma_{i k}=0, \sum_{i} \xi_{i}=0, \quad \sum_{i} \lambda_{i}=0 ; \\
\text { (Homogeneidade) } & \sum_{k} \gamma_{i k}=0 ; \\
\text { (Simetria) } & \gamma_{i k}=\gamma_{k i} .
\end{array}
$$

Adiciona-se um termo de erro a equação (8) referente a cada item de consumo com o objetivo de estimar os parâmetros do modelo. Além disso, insere-se um vetor de características demográficas que contém variáveis dummy de sexo e educação do chefe da família e uma dummy de ano. Os dados de consumo são referentes às Pesquisas de Orçamentos Familiares de 2002/2003 e 2008/2009, enquanto os dados de preços foram obtidos a partir de um vetor de preços para produtos não-alimentares com referência em setembro de 1999 , disponibilizado pelo IBGE $^{3}$. No entanto, as informações de preço se limitam as regiões metropolitanas de Belém, Fortaleza, Recife, Salvador, Belo Horizonte, Rio de Janeiro, São Paulo, Curitiba, Porto Alegre, Goiânia e Brasília, o que reduz o tamanho da amostra. Além disso, retirou-se da amostra aquelas famílias com despesa total menor que um salário mínimo ou maior do que 40 salários mínimos, deixando a amostra com 12.652 observações.

A estratégia econométrica adotada é a estimação de um Sistema Não-Linear de Regressões Aparentemente Não-Relacionadas (NLSUR) usando Mínimos Quadrados Generalizados Viáveis Iterados ${ }^{4}$, que estima a matriz de variância-covariância dos erros a partir dos resíduos do modelo não-linear. Dadas as condições de aditividade, a matriz de variância-covariância é singular, portanto o modelo é estimados com uma equação a menos, enquanto os parâmetros da equação excluída são recuperados a partir das condições em (9).

Por fim, para corrigir o problema de endogeneidade causada pela variável despesa, utiliza-se o procedimento adotado por Blundell e Robin (1999), dividindo a estimação em três estágios. No primeiro estágio estima-se uma regressão da despesa em relação à renda total e o vetor de característica demográficas, usando-se os resíduos obtidos como controle no segundo estágio. Soma-se a esses estágios a estimação do NLSUR.

Uma variação de bem-estar pode ser obtida por meio da diferença entre a função utilidade indireta nos dois estados de preços. No modelo QUAIDS a função de utilidade indireta é dada por

$$
\log v^{h}\left(\mathbf{q}, y^{h}\right)=\left[\left(\frac{\log y^{h}-P}{\prod_{i} q_{i}^{\xi_{i}}}\right)^{-1}+\sum_{i} \theta_{i} \log q_{i}\right]^{-1}
$$

No entanto, é mais interessante uma medida que informe a variação de bem-estar em termos monetários. Uma vez que a função gasto é estritamente crescente com a utilidade indireta, é possível

\footnotetext{
${ }^{3}$ Os preços foram corrigidos para os anos de 2003 e 2009 a partir do índice de preços ao consumidor autônomo do IBGE.

${ }^{4}$ Para mais sobre o procedimento computacional ver Poi $(2002,2008)$.
} 
usar a diferença entre o gasto necessário para obter uma utilidade a preços $\mathbf{q}_{1}$, depois da reforma, e o gasto necessário para obter uma utilidade a preços qo, antes da reforma, dado o preço $\overline{\mathbf{q}}$, ou seja, $E\left(\overline{\mathbf{q}}, v\left(\mathbf{q}_{1}, y^{h}\right)\right)-E\left(\overline{\mathbf{q}}, v\left(\mathbf{q}_{0}, y^{h}\right)\right)$, em que utilizando $\overline{\mathbf{q}}=\mathbf{q}_{0}$ temos a variação equivalente.

Sendo a função gasto do modelo QUAIDS dada por

$$
\log E(\mathbf{q}, v)=P+\frac{\prod_{i} q_{i}^{\xi_{i}} \times v}{1+\left(v \times \sum_{i} \theta_{i} \log q_{i}\right)},
$$

temos a seguinte forma para variação equivalente:

$$
\Psi^{h}=\exp \left(P_{0}\right)\left[\exp \left(\frac{v^{h}\left(\mathbf{q}_{1}, y^{h}\right) \prod_{i} q_{0 i}^{\xi_{i}}}{1+v^{h}\left(\mathbf{q}_{1}, y^{h}\right) \theta\left(\mathbf{q}_{0}\right)}\right)-\exp \left(\frac{v^{h}\left(\mathbf{q}_{0}, y^{h}\right) \prod_{i} q_{0 i}^{\xi_{i}}}{1+v^{h}\left(\mathbf{q}_{0}, y^{h}\right) \theta\left(\mathbf{q}_{0}\right)}\right)\right],
$$

em que $\theta(\mathbf{q})=\sum_{i} \theta_{i} \log q_{i}$ e $P_{0}$ é o índice de preço antes da reforma. Na seção 4.2 será apresentada a variação equivalente relativa, $\Psi_{r}^{h}$, que reflete a variação de bem-estar como proporção da despesa total da famílias. Portanto, uma valor negativo de $\Psi_{r}^{h}$ representa uma perda de bem-estar da família $h$ e um valor positivo, um ganho de bem-estar.

\section{RESULTADOS}

\subsection{Características Distributivas}

Nesta subseção, o objetivo é identificar os itens de consumo com maior capacidade distributiva a partir das características distributivas. Como mostrado nas seções anteriores, a característica distributiva de um bem reflete o quanto esse bem é importante na cesta de consumo de famílias com elevados pesos sociais. Dessa forma, usa-se essa medida para sugerir reformas tributárias que visem tornar o sistema tributário indireto progressivo.

Figura 1: Pesos sociais médios por centésimos de despesa per capita

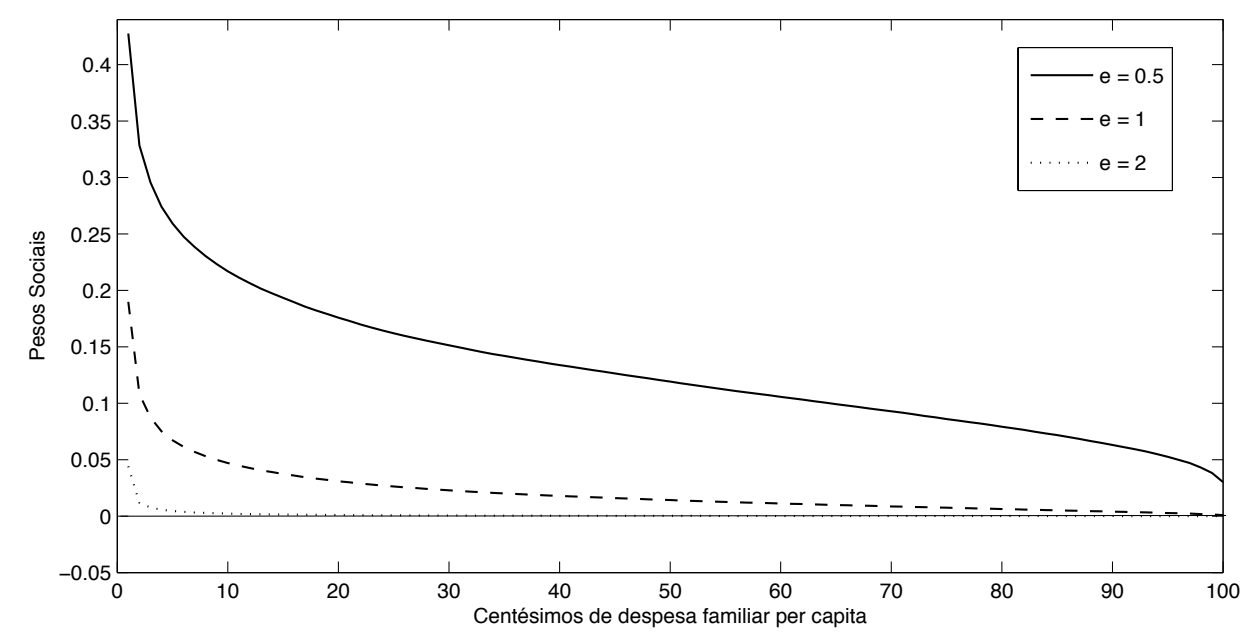

Fonte: elaboração própria. Dados: pesquisa de orçamento familiar 2008-2009, IBGE.

Os resultados foram obtidos a partir da equação (6), da subseção 3.1. Deve-se perceber que a característica distributiva de um bem depende de dois componentes: a participação do consumo de cada 
família no consumo total e pesos sociais. Os padrões de consumo já foram analisados na seção 2. Por sua vez, a Figura 1 mostra os valores médios dos pesos sociais para os centésimos de despesa domiciliar per capita. Observe como os valores dos pesos caem mais rapidamente para zero à medida que o nível de aversão à desigualdade aumenta. Um valor de $e=2$ já representa um grau de aversão alto, uma vez que antes do vigésimo centésimo de despesa os pesos já são muito próximos de zero. Assim, apenas as famílias com gastos per capita mais baixos influenciam no valor da característica distributiva.

A Tabela 4 mostra as características distributivas para os itens estudados, com três diferentes níveis de aversão à desigualdade. Nota-se que não há alterações significativas devido a mudanças na aversão à desigualdade no topo da tabela. Os itens com maiores características distributivas, para os três níveis de aversão, são combustível doméstico e fumo. Transporte público encontra-se em terceiro lugar, para $e=0,5$, enquanto cesta básica assume essa posição para valores mais elevados. Observe que eletricidade e aluguel sobem uma posição no último nível de aversão a desigualdade, enquanto transporte público cai para sexta posição.

Tabela 4: Características distributivas para diferentes níveis de aversão à desigualdade $(e)$

\begin{tabular}{lcccccc}
\hline \multirow{2}{*}{ Item } & \multicolumn{7}{c}{ Característica Distributiva } \\
\cline { 2 - 7 } & $e=0,5$ & Posto & $e=1$ & Posto & $e=2$ & Posto \\
\hline Combustível doméstico & 0,97 & 1 & 0,92 & 1 & 0,73 & 1 \\
Fumo & 0,87 & 2 & 0,74 & 2 & 0,48 & 2 \\
Cesta Básica & 0,84 & 4 & 0,69 & 3 & 0,40 & 3 \\
Transporte público & 0,84 & 3 & 0,67 & 4 & 0,34 & 6 \\
Eletricidade & 0,80 & 5 & 0,64 & 5 & 0,39 & 4 \\
Aluguel & 0,77 & 6 & 0,61 & 6 & 0,37 & 5 \\
Higiene e cuidados pessoais & 0,74 & 7 & 0,54 & 7 & 0,27 & 8 \\
Vestuário & 0,72 & 9 & 0,53 & 8 & 0,27 & 7 \\
Outros alimentos & 0,72 & 8 & 0,52 & 9 & 0,25 & 9 \\
Recreação e cultura & 0,68 & 11 & 0,47 & 10 & 0,22 & 10 \\
Comunicação & 0,68 & 10 & 0,46 & 11 & 0,18 & 13 \\
Saúde & 0,67 & 12 & 0,45 & 12 & 0,21 & 11 \\
Bens e serviços domésticos & 0,65 & 13 & 0,44 & 13 & 0,21 & 12 \\
Educação & 0,58 & 16 & 0,34 & 14 & 0,14 & 14 \\
Outros bens e serviços & 0,58 & 17 & 0,34 & 15 & 0,11 & 15 \\
Combustível automotivo & 0,59 & 15 & 0,33 & 16 & 0,09 & 16 \\
Bebidas alcoólicas & 0,59 & 14 & 0,33 & 17 & 0,08 & 18 \\
Transporte privado & 0,53 & 18 & 0,28 & 18 & 0,08 & 17 \\
\hline
\end{tabular}

Fonte: elaboração própria. Dados: Pesquisa de Orçamento Familiar, IBGE.

Com baixa aversão à desigualdade, os itens com menores características distributivas são transporte privado, outros bens e serviços e educação. Combustível automotivo e bebidas alcoólicas vêm logo abaixo. Com $e=1$, transporte privado continua com a menor característica distributiva, no entanto, bebidas alcoólicas e combustível automotivo caem no ranking assumindo as posições 17 e 16 , respectivamente. Com um nível de aversão à desigualdade igual a 2 , a única mudança é a troca de posições entre bebidas alcoólicas e transporte privado, tornando o primeiro aquele item com menor poder de redistribuir renda. 
Os itens candidatos a participar do grupo de alíquotas reduzidas são basicamente aqueles cuja participação no gasto total das famílias dos décimos de despesa inferiores é maior, como cesta básica e combustível doméstico. Aqueles cujas alíquotas podem ser aumentadas são os itens de consumo prevalecentes sobre a cesta dos décimos de despesa maiores, como, por exemplo, transporte privado. Vale lembrar que essa análise não leva em consideração externalidades causadas pelo consumo dos bens. Dessa forma, a redução de alíquota de fumo, apesar do elevado poder distributivo, seria irrealista devido aos diversos problemas resultantes do consumo desse item.

\subsection{Impacto de reformas sobre o bem-estar das famílias}

Nesta subseção, usam-se as características distributivas para avaliar o impacto sobre o bem-estar das famílias de reformas no sistema tributário. Para facilitar a estimativa do sistema de demanda, os itens de consumo foram agregados em 13 grupos. Eletricidade foi agrupada com combustível doméstico, combustível automotivo com transporte privado, bebidas alcoólicas com fumo e saúde com educação. Além disso, o item outros bens e serviços foi excluído uma vez que não temos informações de preços para esse grupo.

Como o objetivo é simular reformas que mantenham a receita do governo inalterada, a Tabela 5 apresenta cinco estruturas de alíquotas que representam esse propósito. Para obtê-las, usam-se os parâmetros do modelo QUAIDS, cujas estimativas são apresentadas no apêndice A, de forma a estimar o consumo das famílias e, assim, a receita do governo. Normalizam-se os preços do produtor de forma que o preço da economia depende apenas da alíquota efetiva tal que

$$
q_{i}=\frac{1}{1-\tau_{i}}
$$

Note que essa normalização é consistente com a hipótese de que os preços de produtores são fixos e, implicitamente, define a unidade de cada bem como aquela quantidade que custa uma unidade monetária a preços de produtor.

A escolha das reformas apresentadas na Tabela 5 foi feita com o intuito de testar o impacto sobre o bem-estar das famílias de estruturas de alíquotas com níveis diferentes de seletividade. Foram testadas estruturas com no máximo quatro níveis diferentes de alíquotas, de forma a reduzir a complexidade do sistema e limitar custos administrativos. A escolha de quais itens encaixar na alíquota reduzida, na alíquota padrão ou na alíquota elevada foi feita com base nas características distributivas e, em alguns casos, buscou-se capturar algumas das ideias correntes do debate sobre reforma tributária no Brasil, como, por exemplo, isenção da cesta básica na reforma 2.

A primeira reforma mostra uma estrutura de alíquotas uniformes. Todos os itens são tributados com a alíquota efetiva de $17,9 \%$. No segundo cenário, exoneram-se os itens cesta básica e eletricidade e combustível doméstico, uma vez que possuem características distributivas mais elevadas, e tributa-se o restante dos itens a uma alíquota uniforme, com exceção de bebidas alcoólicas e fumo que são mantidos com alíquotas inalteradas devido às externalidades de consumo. A reforma 3 tem uma alíquota padrão de $22,1 \%$ e uma alíquota reduzida de $11,1 \%$ para os itens cesta básica, eletricidade e combustível doméstico e transporte público e aluguel, além da alíquota de 43,4\% para bebidas alcoólicas e fumo. Na quarta e quinta reformas, as alíquotas se diferenciam em 3 níveis, além de bebidas alcoólicas e fumo. A reforma 4 tem alíquota reduzida de $8,9 \%$, metade da alíquota padrão de $17,8 \%$, e uma alíquota $50 \%$ mais elevada sobre bens e serviços domésticos, combustível automotivo e transporte privado e saúde e educação. Por fim, na reforma 5, a alíquota incidente sobre o grupo combustível automotivo e transporte privado e o grupo saúde e educação é aumentada para $40,2 \%$, enquanto que a alíquota incidente sobre os grupos cesta básica , eletricidade e combustível doméstico, transporte público e aluguel é reduzida para 4,5\%.

A Tabela 6 mostra os ganhos de bem-estar na forma de variação equivalente relativa (isto é, como proporção da despesa familiar total) para cada décimo de despesa familiar. A primeira reforma, cuja estrutura é uniforme, apresenta perda de bem-estar para as famílias dos sete primeiros décimos, enquanto 
Tabela 5: Reformas tributárias neutras em termos de arrecadação (\%)

\begin{tabular}{lcccccc}
\hline \multicolumn{1}{c}{ Item } & Antes & Reforma 1 & Reforma 2 & Reforma 3 & Reforma 4 & Reforma 5 \\
\hline Cesta Básica & 13,00 & 17,90 & 0,00 & 11,10 & 8,90 & 4,50 \\
Outros Alimentos & 18,44 & 17,90 & 21,00 & 22,10 & 17,80 & 13,40 \\
Bebidas e Fumo & 43,44 & 17,90 & 43,40 & 43,40 & 43,40 & 43,40 \\
Vestuário & 13,51 & 17,90 & 21,00 & 22,10 & 17,80 & 13,40 \\
Eletricidade e Comb. & 37,49 & 17,90 & 0,00 & 11,10 & 8,90 & 4,50 \\
Bens e Serviços Dom & 18,41 & 17,90 & 21,00 & 22,10 & 26,70 & 13,40 \\
Transporte Privado & 24,07 & 17,90 & 21,00 & 22,10 & 26,70 & 40,20 \\
Saúde e Educação & 16,62 & 17,90 & 21,00 & 22,10 & 26,70 & 40,20 \\
Transporte Público & 17,00 & 17,90 & 21,00 & 11,10 & 8,90 & 4,50 \\
Comunicação & 38,97 & 17,90 & 21,00 & 22,10 & 17,80 & 13,40 \\
Higiene e Cuidados & 22,46 & 17,90 & 21,00 & 22,10 & 17,80 & 13,40 \\
Recreação e Cultura & 30,68 & 17,90 & 21,00 & 22,10 & 17,80 & 13,40 \\
Aluguel & 0,75 & 17,90 & 21,00 & 11,10 & 8,90 & 4,50 \\
\hline
\end{tabular}

Fonte: elaboração própria.

os demais décimos têm aumento de bem-estar, chegando a maior perda a representar, em média, 2,94\% da despesa do décimo mais pobre. Na segunda reforma, a variação equivalente relativa é decrescente com os décimos de despesa, mostrando que essa reforma resulta em ganhos de bem-estar relativamente maiores para os décimos mais baixos. Os cinco últimos décimos apresentam perda de bem-estar, enquanto o primeiro décimo experimenta um ganho de bem-estar equivalente a um aumento de $0,23 \%$ em sua despesa, em média.

Tabela 6: Variação equivalente relativa para cinco reformas tributárias

\begin{tabular}{cccccc}
\hline \multirow{2}{*}{ Décimos de Despesa } & \multicolumn{5}{c}{ Variação Equivalente relativa (\%) } \\
\cline { 2 - 6 } & Reforma 1 & Reforma 2 & Reforma 3 & Reforma 4 & Reforma 5 \\
\hline 1 & $-2,94$ & 0,23 & 1,16 & 2,89 & 8,27 \\
2 & $-1,73$ & 0,22 & 0,84 & 1,93 & 5,43 \\
3 & $-1,25$ & 0,17 & 0,69 & 1,46 & 4,16 \\
4 & $-0,85$ & 0,10 & 0,54 & 1,05 & 3,05 \\
5 & $-0,59$ & 0,04 & 0,43 & 0,75 & 2,27 \\
6 & $-0,31$ & $-0,04$ & 0,30 & 0,39 & 1,35 \\
7 & $-0,03$ & $-0,15$ & 0,15 & $-0,01$ & 0,38 \\
8 & 0,32 & $-0,31$ & $-0,05$ & $-0,54$ & $-0,92$ \\
9 & 0,70 & $-0,56$ & $-0,33$ & $-1,27$ & $-2,60$ \\
10 & 1,15 & $-1,15$ & $-0,88$ & $-2,62$ & $-5,56$ \\
\hline
\end{tabular}

Fonte: elaboração própria. 
Na reforma 3, a distribuição dos ganhos é semelhante, porém são maiores para todos os níveis de despesa, tanto que o sexto e o sétimo décimos passam a apresentar ganhos de bem-estar. A reforma 4 também gera ganhos decrescentes com a despesa, no entanto, os décimos mais baixos aumentam seus ganhos enquanto os mais altos aumentam suas perdas. 0 primeiro décimo ganha, em média, 0 equivalente a $2,89 \%$ da sua despesa e o décimo mais alto perde, em média, $2,62 \%$ da despesa. Isso reflete a diminuição das alíquotas de itens com característica distributivas elevadas frente a um aumento de alíquotas sobre itens com baixas características distributivas. Esse efeito é ampliado na reforma 5, em que a estrutura de alíquota se assemelha a da reforma 4, porém com uma diferença maior entre as alíquotas. Nesse caso, o ganho dos estratos de despesa mais baixos é ainda maior, chegando o primeiro décimo a ganhar o equivalente, em média, a $8,27 \%$ de sua despesa total, enquanto o décimo mais alto sofre uma perda equivalente, em média, a 5,56\% despesa.

\section{CONCLUSÕES}

Este trabalho calculou as características distributivas dos bens e serviços consumidos pelas famílias no Brasil usando a POF 2008-2009. O cálculo das características distributivas permite ordenar os bens de acordo com sua participação na cesta de consumo das famílias com maiores pesos sociais. Essa informação foi utilizada como guia na elaboração de propostas alternativas de reforma tributária. 0 impacto das reformas sobre o bem-estar das famílias foi, então, avaliado usando o conceito de "variação equivalente" e o sistema de demanda quase ideal na forma quadrática (QUAIDS).

Os resultados mostram que os três itens de consumo familiar com características distributivas mais elevadas são combustível doméstico , fumo e cesta básica , e os três itens com características distributivas mais baixas são combustível automotivo, bebidas alcoólicas e transporte privado. Observou-se que a ordenação dos bens de acordo com suas características distributivas é bastante insensível ao grau de aversão à desigualdade. Foram avaliadas cinco reformas, sendo uma delas com alíquotas uniformes. O impacto dessa sobre o bem-estar das famílias é regressivo ao contrário das reformas baseadas nas características distributivas que, como esperado, são progressivas. A mais progressiva resulta em um aumento de bem-estar para as famílias mais pobres (primeiro décimo) equivalente a um aumento de $8,27 \%$ em seu consumo total, e em uma perda de bem-estar para as famílias mais ricas (último décimo) equivalente a uma redução de 5,56\% em seu consumo total. 


\section{BIBLIOGRAFIA}

Ahmad, E. \& Stern, N. (1984). The theory of reform and Indian indirect taxes. Journal of Public Economics, 25(3):259-298

Ahmad, E. \& Stern, N. (1991). The theory and practice of tax reform in developing countries. Cambridge Univiverty Press.

Atkinson, A. (1970). On the measurement of inequality. Journal of Economic Theory, 2(3):244-263.

Banks, J., Blundell, R., \& Lewbel, A. (1997). Quadratic Engel Curves And Consumer Demand. The Review of Economics and Statistics, 79(4):527-539.

Blundell, R. \& Robin, J. M. (1999). Estimation in Large and Disaggregated Demand Systems: An Estimator for Conditionally Linear Systems. Journal of Applied Econometrics, 14(3):209-32.

Deaton, A. S. \& Muellbauer, J. (1980). An almost ideal demand system. American Economic Review, 70(3):312-26.

Dixit, A. (1975). Welfare effects of tax and price changes. Journal of Public Economics, 4(2):103 - 123.

Feldstein, M. S. (1972). Distributional equity and the optimal structure of public prices. The American Economic Review, 62(1/2):32-36.

IBGE (2008). Matriz Insumo-Produto - Brasil: 2000/2005. Rio de Janeiro.

Ministério da Fazenda (2008). Reforma Tributária.

Newbery, D. M. (1995). The distributional impact of price changes in Hungary and the United Kingdom. The Economic Journal, 105(431):847-863.

Poi, B. P. (2002). From the help desk: Demand system estimation. Stata Journal, 2(4):403-410.

Poi, B. P. (2008). Demand-system estimation: Update. Stata Journal, 8(4):554-556.

Secretaria da Receita Federal (2010). Carga Tributária no Brasil: Análise por tributos e bases de incidência. Estudos Tributários 21, Receita Federal.

Siqueira, R. B. d., Nogueira, J. R. B., \& Souza, E. S. d. (2012). O sistema tributário brasileiro é regressivo? http://www.joserobertoafonso.com.br/attachments/article/2508/siqueira, $\backslash \% 20$ nogueira $\backslash \% 20$ e $\% 20$ souza $\backslash \% 20(2012)$.pdf.

Siqueira, R. B. d., R.B., N. J., \& Souza, E. S. d. (2011). Alíquotas efetivas e a distribuição da carga tributária indireta entre as famílias no Brasil. In XV Prêmio Tesouro Nacional 2010. Secretaria do Tesouro Nacional - Ministério da Fazenda. 


\section{A. ESTIMAÇÕES}

Tabela A-1: Estimação do modelo QUAIDS

\begin{tabular}{|c|c|c|c|c|c|c|}
\hline Parâmetro & Coeficiente & Erro padrão & $z$ & $P>|z|$ & \multicolumn{2}{|c|}{ Intervalo de confiança $95 \%$} \\
\hline$\alpha_{1}$ & 0,203249 & 0,020571 & 9,88 & 0 & 0,162931 & 0,243566 \\
\hline$\alpha_{2}$ & 0,101174 & 0,009273 & 10,91 & 0 & 0,083 & 0,119349 \\
\hline$\alpha_{3}$ & $-0,00243$ & 0,007472 & $-0,32$ & 0,745 & $-0,01707$ & 0,012218 \\
\hline$\alpha_{4}$ & 0,03027 & 0,010417 & 2,91 & 0,004 & 0,009852 & 0,050687 \\
\hline$\alpha_{5}$ & 0,126296 & 0,008298 & 15,22 & 0 & 0,110033 & 0,14256 \\
\hline$\alpha_{6}$ & 0,052458 & 0,019668 & 2,67 & 0,008 & 0,013911 & 0,091006 \\
\hline$\alpha_{7}$ & $-0,02075$ & 0,016832 & $-1,23$ & 0,218 & $-0,05374$ & 0,012237 \\
\hline$\alpha_{8}$ & $-0,03021$ & 0,02036 & $-1,48$ & 0,138 & $-0,07011$ & 0,009696 \\
\hline$\alpha_{9}$ & 0,140535 & 0,009645 & 14,57 & 0 & 0,121631 & 0,15944 \\
\hline$\alpha_{10}$ & 0,01445 & 0,008168 & 1,77 & 0,077 & $-0,00156$ & 0,030459 \\
\hline$\alpha_{11}$ & 0,023537 & 0,002142 & 10,99 & 0 & 0,019338 & 0,027736 \\
\hline$\alpha_{12}$ & $-0,02015$ & 0,011456 & $-1,76$ & 0,079 & $-0,0426$ & 0,002301 \\
\hline$\xi_{1}$ & $-0,05312$ & 0,005332 & $-9,96$ & 0 & $-0,06357$ & $-0,04267$ \\
\hline$\xi_{2}$ & 0,032859 & 0,005058 & 6,5 & 0 & 0,022945 & 0,042773 \\
\hline$\xi_{3}$ & 0,001409 & 0,001801 & 0,78 & 0,434 & $-0,00212$ & 0,004939 \\
\hline$\xi_{4}$ & $-0,0089$ & 0,003204 & $-2,78$ & 0,005 & $-0,01518$ & $-0,00262$ \\
\hline$\xi_{5}$ & $-0,05591$ & 0,001933 & $-28,93$ & 0 & $-0,0597$ & $-0,05212$ \\
\hline$\xi_{6}$ & 0,017279 & 0,00532 & 3,25 & 0,001 & 0,006852 & 0,027705 \\
\hline$\xi_{7}$ & 0,086715 & 0,007798 & 11,12 & 0 & 0,071431 & 0,101999 \\
\hline$\xi_{8}$ & 0,065575 & 0,005099 & 12,86 & 0 & 0,055583 & 0,075568 \\
\hline$\xi_{9}$ & $-0,02903$ & 0,003529 & $-8,23$ & 0 & $-0,03595$ & $-0,02212$ \\
\hline$\xi_{10}$ & 0,023197 & 0,002352 & 9,86 & 0 & 0,018589 & 0,027806 \\
\hline$\xi_{11}$ & 0,007151 & 0,001916 & 3,73 & 0 & 0,003397 & 0,010906 \\
\hline$\xi_{12}$ & 0,026026 & 0,002641 & 9,85 & 0 & 0,02085 & 0,031202 \\
\hline$\gamma_{11}$ & $-0,01594$ & 0,012502 & $-1,28$ & 0,202 & $-0,04044$ & 0,008563 \\
\hline$\gamma_{12}$ & $-0,01988$ & 0,002338 & $-8,51$ & 0 & $-0,02447$ & $-0,0153$ \\
\hline$\gamma_{13}$ & 0,023511 & 0,003512 & 6,69 & 0 & 0,016627 & 0,030395 \\
\hline$\gamma_{14}$ & 0,013172 & 0,004363 & 3,02 & 0,003 & 0,004621 & 0,021723 \\
\hline$\gamma_{15}$ & $-0,03272$ & 0,004192 & $-7,81$ & 0 & $-0,04094$ & $-0,0245$ \\
\hline$\gamma_{16}$ & 0,014173 & 0,00798 & 1,78 & 0,076 & $-0,00147$ & 0,029813 \\
\hline$\gamma_{17}$ & 0,053446 & 0,005785 & 9,24 & 0 & 0,042108 & 0,064785 \\
\hline
\end{tabular}




\begin{tabular}{|c|c|c|c|c|c|c|}
\hline Parâmetro & Coeficiente & Erro padrão & $z$ & $P>|z|$ & \multicolumn{2}{|c|}{ Intervalo de confiança 95\% } \\
\hline$\gamma_{18}$ & $-0,01655$ & 0,007425 & $-2,23$ & 0,026 & $-0,03111$ & $-0,002$ \\
\hline$\gamma_{19}$ & $-0,01557$ & 0,003291 & $-4,73$ & 0 & $-0,02202$ & $-0,00912$ \\
\hline$\gamma_{110}$ & 0,004262 & 0,003739 & 1,14 & 0,254 & $-0,00307$ & 0,01159 \\
\hline$\gamma_{111}$ & $-0,01889$ & 0,00366 & $-5,16$ & 0 & $-0,02607$ & $-0,01172$ \\
\hline$\gamma_{112}$ & 0,025924 & 0,005818 & 4,46 & 0 & 0,01452 & 0,037328 \\
\hline$\gamma_{22}$ & $-0,00432$ & 0,001917 & $-2,25$ & 0,024 & $-0,00808$ & $-0,00056$ \\
\hline$\gamma_{23}$ & $-0,00118$ & 0,000838 & $-1,41$ & 0,158 & $-0,00282$ & 0,00046 \\
\hline$\gamma_{24}$ & $-0,00093$ & 0,001308 & $-0,71$ & 0,478 & $-0,00349$ & 0,001635 \\
\hline$\gamma_{25}$ & $-0,00321$ & 0,000955 & $-3,36$ & 0,001 & $-0,00508$ & $-0,00134$ \\
\hline$\gamma_{26}$ & $-0,00129$ & 0,002264 & $-0,57$ & 0,567 & $-0,00573$ & 0,003143 \\
\hline$\gamma_{27}$ & 0,026748 & 0,002432 & 11 & 0 & 0,021981 & 0,031515 \\
\hline$\gamma_{28}$ & 0,00219 & 0,002086 & 1,05 & 0,294 & $-0,0019$ & 0,006279 \\
\hline$\gamma_{29}$ & $-0,00723$ & 0,001316 & $-5,5$ & 0 & $-0,00981$ & $-0,00465$ \\
\hline$\gamma_{210}$ & $-0,00192$ & 0,000994 & $-1,93$ & 0,053 & $-0,00387$ & $2,57 \mathrm{E}-05$ \\
\hline$\gamma_{211}$ & $-0,00318$ & 0,000921 & $-3,45$ & 0,001 & $-0,00498$ & $-0,00137$ \\
\hline$\gamma_{212}$ & $-0,00176$ & 0,001225 & $-1,43$ & 0,152 & $-0,00416$ & 0,000645 \\
\hline$\gamma_{33}$ & $-0,00349$ & 0,002128 & $-1,64$ & 0,101 & $-0,00766$ & 0,00068 \\
\hline$\gamma_{34}$ & 0,001552 & 0,001849 & 0,84 & 0,401 & $-0,00207$ & 0,005175 \\
\hline$\gamma_{35}$ & $-0,00255$ & 0,001968 & $-1,3$ & 0,195 & $-0,00641$ & 0,001307 \\
\hline$\gamma_{36}$ & 0,00013 & 0,003129 & 0,04 & 0,967 & $-0,006$ & 0,006263 \\
\hline$\gamma_{37}$ & $-0,00656$ & 0,001892 & $-3,47$ & 0,001 & $-0,01027$ & $-0,00285$ \\
\hline$\gamma_{38}$ & $-0,00796$ & 0,002639 & $-3,02$ & 0,003 & $-0,01313$ & $-0,00279$ \\
\hline$\gamma_{39}$ & $-0,00174$ & 0,001254 & $-1,39$ & 0,165 & $-0,0042$ & 0,000717 \\
\hline$\gamma_{310}$ & $-0,00338$ & 0,001299 & $-2,6$ & 0,009 & $-0,00593$ & $-0,00084$ \\
\hline$\gamma_{311}$ & 0,005733 & 0,001962 & 2,92 & 0,003 & 0,001888 & 0,009578 \\
\hline$\gamma_{312}$ & $-0,0022$ & 0,002657 & $-0,83$ & 0,407 & $-0,00741$ & 0,003004 \\
\hline$\gamma_{44}$ & 0,006368 & 0,003297 & 1,93 & 0,053 & $-9,4 \mathrm{E}-05$ & 0,01283 \\
\hline$\gamma_{45}$ & 0,001119 & 0,00237 & 0,47 & 0,637 & $-0,00353$ & 0,005764 \\
\hline$\gamma_{46}$ & 0,01134 & 0,00402 & 2,82 & 0,005 & 0,003462 & 0,019219 \\
\hline$\gamma_{47}$ & 0,017408 & 0,002826 & 6,16 & 0 & 0,011869 & 0,022948 \\
\hline$\gamma_{48}$ & $-0,01787$ & 0,003392 & $-5,27$ & 0 & $-0,02452$ & $-0,01122$ \\
\hline$\gamma_{49}$ & $-0,00333$ & 0,001924 & $-1,73$ & 0,083 & $-0,0071$ & 0,000436 \\
\hline$\gamma_{410}$ & $-0,01089$ & 0,001707 & $-6,38$ & 0 & $-0,01423$ & $-0,00754$ \\
\hline$\gamma_{411}$ & $-0,00409$ & 0,002539 & $-1,61$ & 0,107 & $-0,00906$ & 0,000889 \\
\hline
\end{tabular}




\begin{tabular}{|c|c|c|c|c|c|c|}
\hline Parâmetro & Coeficiente & Erro padrão & $z$ & $P>|z|$ & \multicolumn{2}{|c|}{ Intervalo de confiança 95\% } \\
\hline$\gamma_{412}$ & $-0,01042$ & 0,002894 & $-3,6$ & 0 & $-0,01609$ & $-0,00474$ \\
\hline$\gamma_{55}$ & 0,019511 & 0,003425 & 5,7 & 0 & 0,012799 & 0,026223 \\
\hline$\gamma_{56}$ & $-0,01766$ & 0,004027 & $-4,38$ & 0 & $-0,02555$ & $-0,00977$ \\
\hline$\gamma_{57}$ & 0,00856 & 0,002099 & 4,08 & 0 & 0,004445 & 0,012674 \\
\hline$\gamma_{58}$ & 0,007225 & 0,002956 & 2,44 & 0,015 & 0,001431 & 0,013019 \\
\hline$\gamma_{59}$ & 0,002114 & 0,001431 & 1,48 & 0,14 & $-0,00069$ & 0,004919 \\
\hline$\gamma_{510}$ & 0,020266 & 0,00152 & 13,33 & 0 & 0,017286 & 0,023246 \\
\hline$\gamma_{511}$ & $-0,01189$ & 0,002399 & $-4,96$ & 0 & $-0,01659$ & $-0,00719$ \\
\hline$\gamma_{512}$ & 0,008315 & 0,003092 & 2,69 & 0,007 & 0,002254 & 0,014376 \\
\hline$\gamma_{66}$ & 0,004658 & 0,009611 & 0,48 & 0,628 & $-0,01418$ & 0,023494 \\
\hline$\gamma_{67}$ & $-0,00552$ & 0,004951 & $-1,12$ & 0,264 & $-0,01523$ & 0,004179 \\
\hline$\gamma_{68}$ & $-6,5 \mathrm{E}-05$ & 0,006732 & $-0,01$ & 0,992 & $-0,01326$ & 0,013129 \\
\hline$\gamma_{69}$ & 0,007942 & 0,003176 & 2,5 & 0,012 & 0,001717 & 0,014167 \\
\hline$\gamma_{610}$ & $-0,01292$ & 0,002976 & $-4,34$ & 0 & $-0,01875$ & $-0,00709$ \\
\hline$\gamma_{611}$ & 0,010012 & 0,003379 & 2,96 & 0,003 & 0,00339 & 0,016635 \\
\hline$\gamma_{612}$ & $-0,00855$ & 0,004995 & $-1,71$ & 0,087 & $-0,01834$ & 0,001238 \\
\hline$\gamma_{77}$ & $-0,02905$ & 0,006522 & $-4,45$ & 0 & $-0,04183$ & $-0,01627$ \\
\hline$\gamma_{78}$ & $-0,00117$ & 0,004649 & $-0,25$ & 0,801 & $-0,01029$ & 0,007938 \\
\hline$\gamma_{79}$ & $-0,01021$ & 0,002784 & $-3,67$ & 0 & $-0,01567$ & $-0,00475$ \\
\hline$\gamma_{710}$ & $-0,02448$ & 0,002213 & $-11,06$ & 0 & $-0,02881$ & $-0,02014$ \\
\hline$\gamma_{711}$ & 0,005536 & 0,001943 & 2,85 & 0,004 & 0,001729 & 0,009344 \\
\hline$\gamma_{712}$ & $-0,01529$ & 0,002821 & $-5,42$ & 0 & $-0,02082$ & $-0,00976$ \\
\hline$\gamma_{88}$ & 0,002241 & 0,008135 & 0,28 & 0,783 & $-0,0137$ & 0,018185 \\
\hline$\gamma_{89}$ & 0,022436 & 0,002811 & 7,98 & 0 & 0,016927 & 0,027945 \\
\hline$\gamma_{810}$ & 0,011248 & 0,002766 & 4,07 & 0 & 0,005826 & 0,016669 \\
\hline$\gamma_{811}$ & 0,007094 & 0,001276 & 5,56 & 0 & 0,004594 & 0,009594 \\
\hline$\gamma_{812}$ & $-0,01193$ & 0,004054 & $-2,94$ & 0,003 & $-0,01987$ & $-0,00398$ \\
\hline$\gamma_{99}$ & $-0,00043$ & 0,002138 & $-0,2$ & 0,84 & $-0,00462$ & 0,003758 \\
\hline$\gamma_{910}$ & 0,015323 & 0,001332 & 11,5 & 0 & 0,012712 & 0,017934 \\
\hline$\gamma_{911}$ & $-0,00933$ & 0,002757 & $-3,38$ & 0,001 & $-0,01473$ & $-0,00392$ \\
\hline$\gamma_{912}$ & 0,003063 & 0,001887 & 1,62 & 0,105 & $-0,00064$ & 0,006762 \\
\hline$\gamma_{1010}$ & 0,004596 & 0,001822 & 2,52 & 0,012 & 0,001025 & 0,008167 \\
\hline$\gamma_{1011}$ & $-8 \mathrm{E}-05$ & 0,001499 & $-0,05$ & 0,958 & $-0,00302$ & 0,002859 \\
\hline$\gamma_{1012}$ & $-0,00843$ & 0,002001 & $-4,21$ & 0 & $-0,01235$ & $-0,00451$ \\
\hline
\end{tabular}




\begin{tabular}{ccccccc}
\hline Parâmetro & Coeficiente & Erro padrão & $z$ & $P>|z|$ & Intervalo de confiança 95\% \\
\hline$\gamma_{1111}$ & $-0,00069$ & 0,003176 & $-0,22$ & 0,829 & $-0,00691$ & 0,005539 \\
$\gamma_{1112}$ & 0,007308 & 0,002912 & 2,51 & 0,012 & 0,0016 & 0,013016 \\
$\gamma_{1212}$ & 0,000817 & 0,005501 & 0,15 & 0,882 & $-0,00996$ & 0,011599 \\
$\theta_{1}$ & $-3,02 \mathrm{E}-06$ & 0,001022 & 0 & 0,998 & $-0,00201$ & 0,002 \\
$\theta_{2}$ & $-0,00747$ & 0,000985 & $-7,59$ & 0 & $-0,0094$ & $-0,00554$ \\
$\theta_{3}$ & $-0,00084$ & 0,000346 & $-2,43$ & 0,015 & $-0,00152$ & $-0,00016$ \\
$\theta_{4}$ & 0,000116 & 0,000614 & 0,19 & 0,85 & $-0,00109$ & 0,00132 \\
$\theta_{5}$ & 0,005712 & 0,000373 & 15,33 & 0 & 0,004981 & 0,006442 \\
$\theta_{6}$ & 0,001797 & 0,00102 & 1,76 & 0,078 & $-0,0002$ & 0,003797 \\
$\theta_{7}$ & 0,002313 & 0,001497 & 1,54 & 0,122 & $-0,00062$ & 0,005248 \\
$\theta_{8}$ & $-0,0047$ & 0,000946 & $-4,97$ & 0 & $-0,00656$ & $-0,00285$ \\
$\theta_{9}$ & $-0,00035$ & 0,000678 & $-0,52$ & 0,603 & $-0,00168$ & 0,000977 \\
$\theta_{10}$ & $-0,00448$ & 0,00045 & $-9,94$ & 0 & $-0,00536$ & $-0,00359$ \\
$\theta_{11}$ & $-0,00214$ & 0,000369 & $-5,81$ & 0 & $-0,00286$ & $-0,00142$ \\
$\theta_{12}$ & $-0,00342$ & 0,000507 & $-6,76$ & 0 & $-0,00442$ & $-0,00243$ \\
\hline
\end{tabular}

Fonte: Elaboração própria. 


\section{B. GRUPOS DE CONSUMO}

Tabela B-2: Grupos de Consumo

\begin{tabular}{|c|c|}
\hline Grupos de despesa & Descrição \\
\hline Cesta básica & $\begin{array}{l}\text { Arroz, feijão, outros cereais, leguminosas e oleaginosas, café em pó (moído), açúcar (refinado e cristal), leite de vaca } \\
\text { e leite em pó integral, ovos, farinha de trigo, farinha de mandioca, pão francês, óleo de soja, manteiga e margarina, } \\
\text { tubérculos, legumes, verduras, frutas, carne de aves, pescados (frescos e congelados), outras carnes (inclui defumados, } \\
\text { lingüiça, salsicha, mas não patê, mortadela, etc.) }\end{array}$ \\
\hline Outros alimentos & $\begin{array}{l}\text { Café solúvel; outros leites e derivados; outros açúcares e derivados; derivados do arroz, do milho, do trigo; outras farinhas, } \\
\text { massas e derivados; outros panificados; outros óleos; conservas de frutas, legumes e outros vegetais; refrigerantes; outras } \\
\text { bebidas não alcoólicas; outros produtos alimentares industrializados; e alimentação fora do domicílio }\end{array}$ \\
\hline Bebidas alcoólicas & Bebidas alcoólicas \\
\hline Fumo & Fumo \\
\hline Vestuário & Tecidos e armarinho; artigos do vestuário e acessórios; calçados; serviços (costura, conserto, tintura) \\
\hline Combustível doméstico & Gás e outros combustíveis (carvão, querosene, etc.) \\
\hline Eletricidade & Energia elétrica \\
\hline Aluguel & Aluguel e aluguel imputado \\
\hline Bens e serviços do lar & $\begin{array}{l}\text { Eletrodomésticos; têxteis do lar; artigos de limpeza; móveis; outros artigos do lar; condomínio, água e esgoto; serviços } \\
\text { domésticos; consertos de produtos do lar, manutenção do lar; entre outros }\end{array}$ \\
\hline Combustível automotivo & Gasolina; álcool, outros combustíveis para automóveis \\
\hline Transporte Público & Transporte urbano \\
\hline Transporte Privado & $\begin{array}{l}\text { Aquisição de veículos; peças e acessórios; transporte intermunicipal e interestadual; produtos para limpeza e manutenção } \\
\text { de automóveis, serviços (conserto, lavagem, seguros, impostos, pedágio, estacionamento, etc.) }\end{array}$ \\
\hline Comunicação & Serviços de telefone fixo e celular, equipamentos de telefone e telefax; correio \\
\hline Saúde & $\begin{array}{l}\text { Remédios e outros produtos farmacêuticos; aparelhos e instrumentos terapêuticos; serviços de saúde (consultas, exames } \\
\text { laboratoriais, plano de saúde, etc.) }\end{array}$ \\
\hline Educação & Serviços de educação (cursos); livros e periódicos didáticos; outros artigos escolares \\
\hline Higiene pessoal & $\begin{array}{l}\text { perfumaria, cosméticos, sabonetes, instrumentos e produtos de uso pessoal, serviços (cabeleireira, manicure, etc.), entre } \\
\text { outros }\end{array}$ \\
\hline Recreação e cultura & $\begin{array}{l}\text { TV, rádio, som, vídeo, equipamento fotográfico; jornais, livros e periódicos não didáticos; revistas; CDs e DVDs; brinquedos } \\
\text { e jogos; artigos esportivos; jardinagem; alimentos para animais; acesso à internet, TV por assinatura; cinema, teatro, } \\
\text { futebol, entre outros }\end{array}$ \\
\hline Outros bens e serviços & $\begin{array}{l}\text { Seguros; serviços bancários; serviços associativos; serviços profissionais, cerimônias e festas, jogos e apostas; pensões, } \\
\text { mesadas e doações, entre outros }\end{array}$ \\
\hline
\end{tabular}

